\title{
Assessing the Solubility of Silicon Dioxide Particles Using Simulated Lung Fluid"
}

\author{
Rodney R. Larson ${ }^{*}$, Scott G. Story and Kurt T. Hegmann \\ Rocky Mountain Center for Occ \& Env Health, Department of Family and Preventive Medicine, University of Utah, 391 \\ Chipeta Way, Suite C, Salt Lake City, UT 84108, USA
}

\begin{abstract}
Occupational exposure to respirable crystalline silica has the ability to cause silicosis. Silica is also suspected of being associated with an increased risk of lung cancer, kidney disease, rheumatoid arthritis, and other diseases. The specific mechanism(s) of pathogenesis for silicosis and these other potential health concerns remains unclear. This investigation measured dissolution rates of silicon dioxide $\left(\mathrm{SiO}_{2}\right)$ particles in simulated lung fluid to determine the residence times of such particles within the intracellular or extracellular spaces. Silicon dioxide dissolution rates were determined as a function of fluid $\mathrm{pH}$, particle size, and $\mathrm{SiO}_{2}$ concentration and mass. Gamble's solution was used to simulate intracellular and extracellular lung fluids at $\mathrm{pH} 6.0, \mathrm{pH} 6.5$, and $\mathrm{pH} 7.5$. Test samples were paired by $\mathrm{pH}$, particle size, and $\mathrm{SiO}_{2}$ concentration/mass. Sample aliquots of filtered solution were collected over a 28-day test period. Results revealed $\mathrm{SiO}_{2}$ became soluble and the dissolution rate increased with increasing $\mathrm{pH}$ and decreasing particle size. $\mathrm{SiO}_{2}$ concentration and mass also appeared to have some effect on the rate of dissolution. These solubility characteristics appear likely to impact the residence times of particles within biological systems, suggesting a model for exposure and subsequent pathogenesis for systemic silica-related diseases.
\end{abstract}

Keywords: Silicon dioxide, particles, toxicity, lung fluids, solubility, kidney disease, heart disease, lung cancer, COPD, arthritis.

\section{INTRODUCTION}

Exposure to respirable crystalline silica causes silicosis, but it has also been reportedly associated with lung cancer, rheumatoid arthritis, heart disease, kidney disease, COPD, pulmonary tuberculosis, and autoimmune disorders [1-10]. Yet, the pathophysiological mechanisms are unknown, particularly for development of systemic effects [4, 11]. Crystalline silica dust is a common occupational exposure worldwide [1]. China reported 500,000 cases of silicosis and 24,000 annual deaths occurring in each year for the period 1991-1995 [12]. A 2008 report in the International Journal of Occupational Medicine and Environmental Health states that it is estimated there are over 2 million workers in the European Union exposed to crystalline silica, and in Poland, over 50 thousand people work under conditions of silica dust exposure exceeding the occupational exposure limit [13]. A recent report by the Centers for Disease Control and Prevention (CDC) estimates that more than 120,000 workers in the United States are exposed to respirable crystalline silica at or above the NIOSH recommended exposure limit of $0.05 \mathrm{mg} / \mathrm{m}^{3}$ [14]. NIOSH has estimated that at the current occupational exposure limits (OELs); approximately one percent of exposed workers will develop silicosis over a 40 45 year working lifetime [4].

An epidemiological study by NIOSH reported silica exposed sand workers had elevated risks compared with the

*Address correspondence to this author at the Rocky Mountain Center for Occ \& Env Health, Department of Family and Preventive Medicine, University of Utah, 391 Chipeta Way, Suite C, Salt Lake City, UT 84108, USA; Tel: 801-585-3673; Fax: 801 581-7224;

E-mails: rod.larson@hsc.utah.edu, rlarsoncih@aol.com general US population for lung cancer (1.6-fold), pneumoconiosis/silicosis (170-fold), arthritis (4.6-fold), and endstage kidney disease (1.9-fold) [4]. Yet, the mechanism(s) for developing systemic effects are unknown $[4,11]$.

These results suggest silica not only causes silicosis but may be associated with other systemic diseases, possibly through migration from the lungs into the blood stream or via another mechanism [15-17].

Particles that cannot be dissolved in the extracellular fluid of the lung are phagocytized by alveolar macrophages [17-19]. The intracellular fluid within alveolar macrophages is considerably more acidic ( $\mathrm{pH} \sim 5-6)$ than the extracellular fluid $(\mathrm{pH} \sim 7-7.5)$ and lysosomes within the alveolar macrophages are primarily responsible for the decreased $\mathrm{pH}$ of the intracellular fluid $[15,16,18]$. This mechanism allows for dissolution of matter that is not dissolved in the extracellular lung fluid $[17,19,20]$.

Previous research designed to model particle dissolution within the lungs have used lung fluid simulates to represent conditions in both intracellular and extracellular lung fluids [21-23]. The results of studies using lung fluid simulates reveal that dissolution rates found in Gamble's solution were comparable to dissolution clearance rates from in vivo studies [21, 24-26]. It is also important to note that the citrate used in the Gamble's solution replaces proteins while acetate is added to represent organic acids [26]. Therefore, by using complexing agents such as citrates, phosphates, and carbonates, along with the corresponding fluid $\mathrm{pH}$, in vitro chemical solubility studies are accomplished without using alveolar macrophages. The modeling of the translocation of particles through dissolution may provide valuable insights into possible mechanisms of toxicity for silica $[20,25]$. 
The purpose of this research was to measure the solubility of $\mathrm{SiO}_{2}$ as a function of fluid $\mathrm{pH}$, particle size, and $\mathrm{SiO}_{2}$ concentration in Gamble's solution, a simulated lung fluid solution $[26,27]$.

\section{MATERIALS AND METHODS}

A series of experiments was designed to measure the effects of fluid $\mathrm{pH}$, particle size/surface area, and $\mathrm{SiO}_{2}$ concentration on $\mathrm{SiO}_{2}$ dissolution rates. Samples of $5.0 \mu \mathrm{m}$ and $10.0 \mu \mathrm{m} \mathrm{SiO}_{2}$ particles were provided by the Occupational Safety and Health Administration (OSHA) Salt Lake Technical Center, Salt Lake City, Utah. These samples were analyzed by the Department of Metallurgy at the University of Utah to verify particle size using a laser diffraction analyzer and were measured twice. They were found to have an average particle size at $50 \%$ of cumulative volume of $1.9 \mu \mathrm{m}$ and $5.6 \mu \mathrm{m} \mathrm{SiO}_{2}$.

\section{Lung Fluid Preparation}

Three separate batches of Gamble's solution were prepared to produce simulated lung fluid composition as shown in Table 1. The Gambles solution was added to nine liters of distilled water in a large plastic mixing carboy and bubbled with pure carbon dioxide $\left(\mathrm{CO}_{2}\right)$ for 15 minutes. The respective batches of simulated lung fluid were titrated with $\mathrm{H}_{2} \mathrm{SO}_{4}$ to $\mathrm{pH} 6.0, \mathrm{pH} \quad 6.5$ and $\mathrm{pH} 7.5$ to represent approximate conditions within the intracellular and extracellular lung fluid.

Table 1. Composition of Simulated Lung Fluid (SLF) (Gamble's Solution) in mM

\begin{tabular}{|c|c|}
\hline Species & Concentration (mM) \\
\hline \hline $\mathrm{Na}^{+}$ & 150.7 \\
\hline $\mathrm{Ca}^{2+}$ & 0.197 \\
\hline $\mathrm{NH}_{4}{ }^{+}$ & 10 \\
\hline $\mathrm{C}_{2} \mathrm{H}_{5} \mathrm{NO}_{2}{ }^{-}$(glycine) & 5.99 \\
\hline $\mathrm{H}_{2} \mathrm{CO}$ (formaldehyde in methanol) & 67 \\
\hline $\mathrm{Cl}^{-}$ & 126.4 \\
\hline $\mathrm{SO}_{4}{ }^{2-}$ & 0.5 \\
\hline $\mathrm{HCO}_{3}{ }^{-}$ & 27 \\
\hline $\mathrm{HPO}_{4}{ }^{2-}, \mathrm{H}_{2} \mathrm{PO}_{4}^{-}$ & 1.2 \\
\hline $\mathrm{C}_{6} \mathrm{H}_{5} \mathrm{O}_{7}{ }^{3-}(\mathrm{citrate})$ & 0.2 \\
\hline
\end{tabular}

\section{Sample Preparation}

Four hundred $\mathrm{ml}$ of each simulated lung fluid solution (pH 6.0, pH 6.5, and $\mathrm{pH} 7.5$ ) was added separately to empty high-density polyethylene sample bottles to form the different test groups (I, II, and III). One of the following $\mathrm{SiO}_{2}$ mass and particle size samples was added to the test solution for each test group for a total of 12 different blends:
$100 \mathrm{mg}$ of $1.9 \mu \mathrm{m} \mathrm{SiO}_{2}$

$200 \mathrm{mg}$ of $1.9 \mu \mathrm{m} \mathrm{SiO}_{2}$

$100 \mathrm{mg}$ of $5.6 \mu \mathrm{m} \mathrm{SiO}_{2}$

$200 \mathrm{mg}$ of $5.6 \mu \mathrm{m} \mathrm{SiO}_{2}$

The different mass quantities and particle sizes were used to determine the effects of each on $\mathrm{SiO}_{2}$ dissolution. In pilot experiments prior to this research, sample results were significantly affected by the concentration of silica leaching from the glassware into solution. Thus, glass containing apparatus were not used for sample collection, solution storage, or filtration (e.g., glass fiber filters) for any of these experimental results.

Samples were continuously agitated at $100 \mathrm{rpm}$ on an orbital shaker for the duration of the experiment. Control blanks consisting solely of simulated lung fluid were sampled and continuously agitated in the same manner as the test solutions containing $\mathrm{SiO}_{2}$. Solutions were closely monitored for $\mathrm{pH}$ changes occurring during the experiment. However, solutions were not adjusted for any change in $\mathrm{pH}$.

\section{Sample Collection}

Five $\mathrm{ml}$ aliquots of solution were filtered into $7 \mathrm{ml}$ highdensity polyethylene sample vials on days 7, 14, 19, 21, 23, 26 and 28. Aliquots of solution were collected by drawing the solution for each sample through a syringe and filtered with a $0.2 \mu \mathrm{m}$ cellulose acetate syringe filter. Samples were then labeled and stored until analyzed.

\section{Sample and Statistical Analyses}

Samples were analyzed using inductively coupled plasma atomic emission spectroscopy (ICP-AES) to determine the total concentration of silica in solution as well as the percentage of the initial mass of silica that was dissolved. The average Si concentration was determined from three replicate analyses of the same sample. All sample results were corrected by subtracting the analytical results of the sample blanks from the $\mathrm{SiO}_{2}$ sample results.

Dissolution rates were determined by the amount of $\mathrm{Si}$ originally added to the simulated lung fluid solution, and were calculated as ppm Si dissolved per day (ppm Si/day). The original mass of $\mathrm{Si}$ had to be calculated by determining the fraction of $\mathrm{Si}$ in the $\mathrm{SiO}_{2}$ molecule. Since $\mathrm{Si}$ comprises $46.7 \%$ of the $\mathrm{SiO}_{2}$ mass, each sample mass (original mass of $\mathrm{SiO}_{2}$ added to solution) was multiplied by the mass fraction factor to obtain the mass of the original $\mathrm{Si}$. The percentage of dissolved $\mathrm{Si}$ was then calculated by determining the dissolved fraction of Si from the original Si mass.

Statistical analyses of the results were performed using analysis of variance (ANOVA) to compare the means between the three different $\mathrm{pH}$ groups, with each sample in the three $\mathrm{pH}$ test groups matched with samples of similar particle size and $\mathrm{SiO}_{2}$ mass in the other $\mathrm{pH}$ groups. The twosample t-test was used to compare the means between the 1.9 $\mu \mathrm{m}$ and $5.6 \mu \mathrm{m} \mathrm{SiO}_{2}$ particle size test groups and between the $100 \mathrm{mg}$ and $200 \mathrm{mg} \mathrm{SiO}$ test groups. Levels of statistical significance were established at the $\alpha=0.05$ level. 


\section{RESULTS}

\section{Silica Dissolution as a Function of $\mathbf{p H}$}

Results of the dissolution tests according to $\mathrm{pH}$, particle size and $\mathrm{SiO}_{2}$ mass are in Table 2. ANOVA results comparing the means of the sample groups as a function of $\mathrm{pH}$ were significant $(\mathrm{p}<0.001)$. Figs. $(\mathbf{1}, \mathbf{2}$, and $\mathbf{3})$ contain graphs to illustrate the percentage of dissolved silica from the original mass of silica dioxide at both the 100 and 200 $\mathrm{mg}$ mass concentrations, and at each of the $\mathrm{pH}$ levels of 7.5, 6.5, and 6.0. Since samples in the test groups were paired with each other according to $\mathrm{pH}$ and $\mathrm{SiO}_{2}$ mass, dissolution rates relative to the original mass of $\mathrm{SiO}_{2}$ added to the solution were unnecessary for these particular analyses. Results of the two-sample t-test revealed a significant difference between the mean dissolved Si concentrations between the test groups $(\mathrm{p}<0.001)$.

A summary of the results of $\mathrm{Si}$ dissolution based upon the mass of $\mathrm{SiO}_{2}$ particles added to solution is in Table $\mathbf{2}$. Dissolution rates for the two test groups $\left(100 \mathrm{mg} \mathrm{SiO}_{2}\right.$ added, $200 \mathrm{mg} \mathrm{SiO}_{2}$ added) were analyzed as a function of the dissolution relative to the original mass of $\mathrm{Si}$ added to the solution (fraction Si dissolved). Samples for each test group (100 $\mathrm{mg}$ and $200 \mathrm{mg}$ ) were paired to account for dissolution effects relative to $\mathrm{pH}$ and particle size. Analyses showed a possible non-significant trend $(\mathrm{p}<0.10)$.

Table 2. Results of the $\mathrm{SiO}_{2}$ Dissolution Tests

\begin{tabular}{|c|c|c|c|c|c|}
\hline $\mathbf{p H}$ & $\begin{array}{c}\mathbf{S i O}_{2} \\
\text { Mass } \\
(\mathbf{m g})^{*}\end{array}$ & $\begin{array}{c}\text { Particle } \\
\text { Size } \\
(\boldsymbol{\mu m}) * *\end{array}$ & $\begin{array}{c}\text { Dissolved } \\
\text { Si (ppm) }\end{array}$ & $\begin{array}{c}\text { Si } \\
\text { Dissolved } \\
\mathbf{( \% )}\end{array}$ & $\begin{array}{c}\text { Dissolution } \\
\text { Rate } \\
(\mathbf{p p m} / \mathbf{d a y})\end{array}$ \\
\hline \hline 7.5 & 201 & 10.0 & 3.11 & 1.32 & 0.11 \\
\hline 7.5 & 100.5 & 10.0 & 1.85 & 1.58 & 0.06 \\
\hline 7.5 & 200 & 5.0 & 5.69 & 2.43 & 0.24 \\
\hline 7.5 & 101 & 5.0 & 3.66 & 3.10 & 0.14 \\
\hline 6.5 & 200 & 10.0 & 1.27 & 0.54 & 0.05 \\
\hline 6.5 & 101 & 10.0 & 0.56 & 0.47 & 0.03 \\
\hline 6.5 & 200 & 5.0 & 3.03 & 1.30 & 0.11 \\
\hline 6.5 & 100.5 & 5.0 & 3.26 & 2.78 & 0.13 \\
\hline 6.0 & 201 & 10.0 & 0.76 & 0.32 & 0.03 \\
\hline 6.0 & 99.5 & 10.0 & 0.35 & 0.30 & 0.02 \\
\hline 6.0 & 200.5 & 5.0 & 2.79 & 1.19 & 0.08 \\
\hline 6.0 & 100 & 5.0 & 1.01 & 0.86 & 0.04 \\
\hline
\end{tabular}

* $\mathrm{SiO}_{2}$ Mass indicated is the actual mass used in each test; ideal mass to be 100,200

** Particle samples identified as $5 \mu \mathrm{m}$ and $10 \mu \mathrm{m}$, average particle size is $1.9 \mu \mathrm{m}$ and $5.6 \mu \mathrm{m}$.

Table 3 summarizes the measured $\mathrm{pH}$ levels at the point where $\mathrm{pH}$ stability is reached in each set of experimental conditions. The $\mathrm{pH}$ level for all the test solutions increased over the duration of the experiment. The increase in $\mathrm{pH}$ for the samples was uniform within the test groups of the same original $\mathrm{pH}$ level.
Table 3. pH Measurements for Test Groups

\begin{tabular}{|c|c|c|c|}
\hline Day & $\begin{array}{c}\text { Test Group } \\
\mathbf{p H ~ 6 . 0}\end{array}$ & $\begin{array}{c}\text { Test Group } \\
\mathbf{p H} \text { 6.5 }\end{array}$ & $\begin{array}{c}\text { Test Group } \\
\mathbf{p H} \text { 7.5 }\end{array}$ \\
\hline \hline 1 & 6.09 & 6.50 & 7.29 \\
\hline 5 & 6.07 & 6.50 & 7.29 \\
\hline 7 & 6.05 & 6.45 & 7.30 \\
\hline 13 & 6.21 & 6.59 & 7.64 \\
\hline 16 & 6.17 & 6.59 & 7.79 \\
\hline 19 & 6.25 & 6.62 & 7.73 \\
\hline 21 & 6.25 & 6.62 & 7.73 \\
\hline
\end{tabular}

Note: $\mathrm{pH}$ testing shows stable $\mathrm{pH}$ at 21 days, no additional $\mathrm{pH}$ tests conducted.

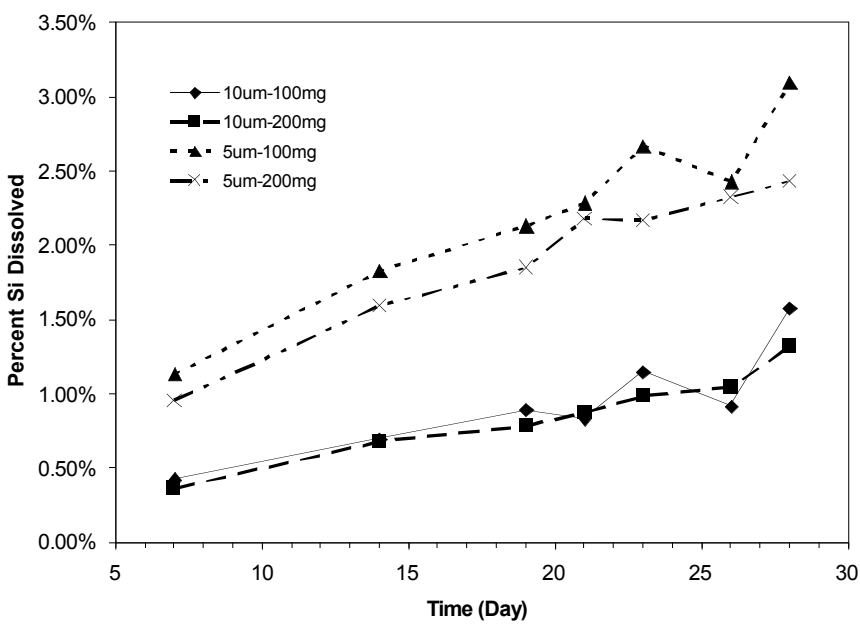

Fig. (1). Percentage of the dissolved silica from the original masses of silica dioxide in the $\mathrm{pH} 7.5$ simulated lung fluid solutions. Plotted data represent the experimental results for tests at $\mathrm{pH} 7.5$ for both particle sizes (5.0 um and $10.0 \mathrm{um})$ and $\mathrm{SiO} 2$ masses $(100 \mathrm{mg}$ and $200 \mathrm{mg}$ ).

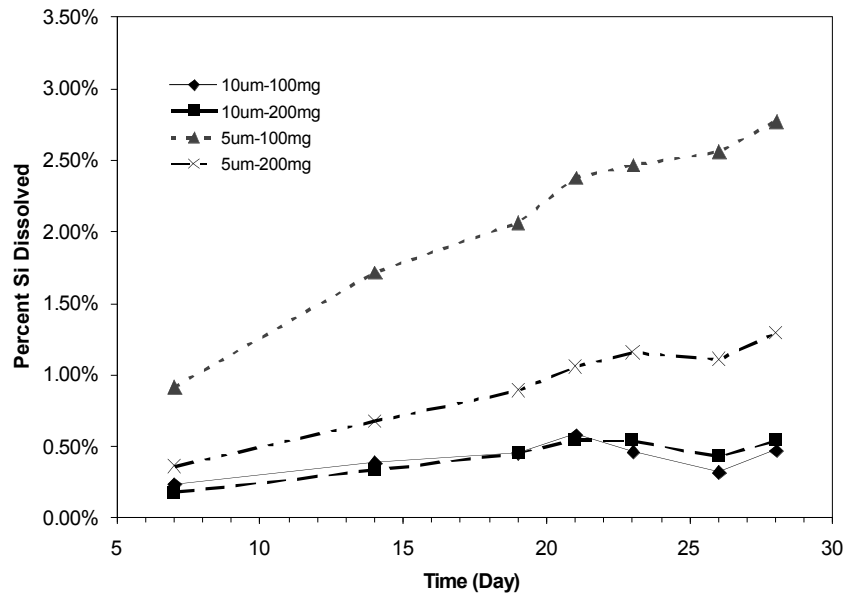

Fig. (2). Percentage of the dissolved silica from the original masses of silica dioxide in the $\mathrm{pH} 6.5$ simulated lung fluid solutions. Plotted data represent the experimental results for tests at $\mathrm{pH} 6.5$ for both particle sizes (5.0 um and $10.0 \mathrm{um}$ ) and $\mathrm{SiO} 2$ masses $(100 \mathrm{mg}$ and $200 \mathrm{mg}$ ). 


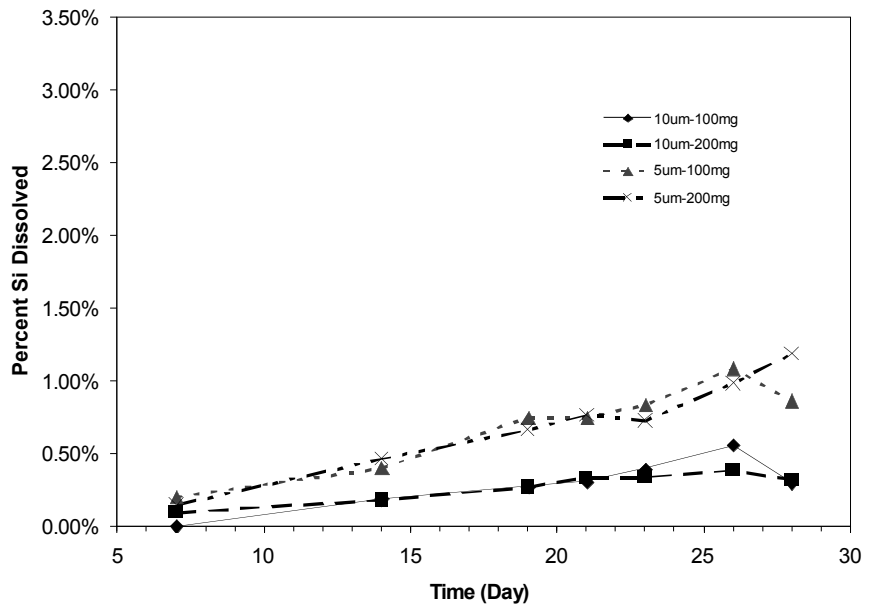

Fig. (3). Percentage of the dissolved silica from the original masses of silica dioxide in the pH 6.0 simulated lung fluid solutions. Plotted data represent the experimental results for tests at $\mathrm{pH} 6.0$ for both particle sizes $(5.0 \mu \mathrm{m}$ and $10.0 \mu \mathrm{m})$ and $\mathrm{SiO} 2$ masses $(100 \mathrm{mg}$ and $200 \mathrm{mg}$ ).

\section{DISCUSSION}

The results of this study found the solubility of silicon dioxide increased significantly with higher $\mathrm{pH}$, smaller particle size, and mass. These results suggest smaller particle size is the most important variable for silica solubility in experimental conditions. This information provides an important theoretical mechanistic basis for transport of soluble silica and the subsequent induction of systemic effects of silica that have been demonstrated in several epidemiological investigations [2-4]. Previously, the pathophysiological mechanism(s) for systemic effects of silicone dioxide have been unknown. These experiments, while not proving a role, suggest the solubility of silicon dioxide in simulated lung fluid adjusted for $\mathrm{pH}$ may provide a potential mechanism for how silicon dioxide may be converted to a soluble form for transport to other tissue in the body. Prior work conducted by Christensen et al. using manmade vitreous fibers and glass fibers in simulated lung fluid solutions revealed that high silica content within the fiber would make a fiber less soluble at lower $\mathrm{pH}[11,15$, 21].

The dissolution rates for the test solutions of different $\mathrm{pH}$ varied quite substantially yet consistently between test groups. The samples that were in solution of $\mathrm{pH} 7.5$ experienced dissolution rates nearly $2.0-3.5$ times greater than those achieved at $\mathrm{pH} 6.5$ and 6.0 respectively. The gradual rise in $\mathrm{pH}$ for the $\mathrm{pH} 7.5$ test group did not appear to have much of an impact on the dissolution rate as the study progressed. It is unclear why the $\mathrm{pH}$ in test group III $(\mathrm{pH}$ 7.5) increased more in comparison to the $\mathrm{pH}$ for the other two test groups ( $\mathrm{pH} 6.5$ and $\mathrm{pH} 6.0$ ).

The results obtained from the particle size/surface area tests, generally correlated with prior studies, which involved surface area as a test parameter for mineral fiber dissolution in simulated lung fluids [23]. On average the dissolution rates for the $1.9 \mu \mathrm{m} \mathrm{SiO}_{2}$ group were approximately twice the rate of corresponding $5.6 \mu \mathrm{m} \mathrm{SiO}_{2}$ group. Previous dissolution research with mineral fibers demonstrated that decreasing surface area or fiber mass was associated with increasing the fiber dissolution rate, regardless of the fiber's composition [23]. Lundborg et al. reported that the dissolution rate of a particle is proportional to the surface area of the particle [19]. Observations by Kanapilly et al. stated that smaller particles of insoluble material would have higher dissolution rates than those of larger particles [24]. However, due to the environment within the intracellular fluid of the macrophage, smaller $\mathrm{SiO}_{2}$ particles $(<5.0 \mu \mathrm{m})$ that are engulfed by alveolar macrophages may experience lower dissolution rates than larger particles that remain in the extracellular lung fluid. These observations correspond with glass fiber dissolution research conducted using cultured nasal epithelial cells and alveolar macrophages [18].

Despite the lack of statistical significance, the analyses conducted on the two test groups of varying $\mathrm{SiO}_{2}$ concentration/mass revealed there may be an effect on the relative dissolution rates based upon concentration of $\mathrm{SiO}_{2}$ in the medium. On average the dissolved fraction of the $100 \mathrm{mg}$ $\mathrm{SiO}_{2}$ group was 1.6 times greater than the dissolved fraction of the $200 \mathrm{mg} \mathrm{SiO}$ group.

The $\mathrm{pH}$ dependent dissolution rate of $\mathrm{SiO}_{2}$ is believed to have physiological significance. Although the exact mechanism for the development of silicosis has not been defined, it is believed that cell death caused by the phagocytized $\mathrm{SiO}_{2}$ particles leads to eventual fibrosis within the lungs. The conditions within alveolar macrophages may enhance residence times for $\mathrm{SiO}_{2}$ particles within the cell, due to the reduced $\mathrm{pH}$ of the intracellular fluid. It is unclear whether silica particles are cytotoxic due to their chemical properties, physical properties, or a combination of the two.

Limitations of this study include a lack of biological components, such as enzymes, that would have an effect on the transport of silica from the lungs into the body. An invivo study may be beneficial for further determination of the extent of solubility of silica dioxide in the lungs and subsequent distribution in the body. However, the lack of biological components would seem unlikely to change the relationships identified in this study.

\section{CONCLUSIONS}

These experiments strongly suggest smaller particle size (e.g., larger surface area) of silica dioxide is more important than mass for producing silica dissolution. Higher $\mathrm{pH}$ also is an important factor. The dissolution rates of $\mathrm{SiO}_{2}$ particles may have important toxicological ramifications. Each parameter that was tested in this research may have important roles in the pathogenesis of silica exposure induced disease. These results are also comparable with observations from particle dissolution research conducted using mineral fibers [21].

There was evidence that increased $\mathrm{SiO}_{2}$ concentration may reduce the overall amount of silica that is dissolved. Based upon the findings of this research as well as previous work, it would appear that $\mathrm{SiO}_{2}$ dissolution occurs at a greater rate in the extracellular lung fluid than in the intracellular fluid.

The impacts of $\mathrm{SiO}_{2}$ dissolution rates on development of silicosis and other diseases associated with respirable 
crystalline silica exposure are unclear. As silica appears to become soluble, it suggests not only the larger particles remaining in the lung may be responsible for silicosis, but the soluble portion may be transported from the lungs into the blood stream and beyond to potentially produce a variety of other adverse effects.

\section{REFERENCES}

[1] Rice FL, Park R, Stayner L, Smith R, Gilbert S, Checkoway H. Crystalline silica exposure and lung cancer mortality in diatomaceous earth industry workers: a quantitative risk assessment. Occup Environ Med 2001; 58: 38-45.

[2] Dufresne A, Begin R, Dion C, et al. Angular and fibrous particles in lung in relation to silica-induced diseases. Int Arch Occup Environ Health 1998; 71: 263-9.

[3] Saffiotti U, Lambert DN, Mao Y, Shi X, Williams AO, Kaighn ME. mechanism of carcinogenesis by crystalline silica in relation to oxygen radicals. Environ Health Perspect 1994; 102(Suppl 10): 159-3.

[4] National Institute for Occupational Safety and Health (US). Health Effects of Occupational Exposure to Respirable Crystalline Silica. Department of Health and Human Services Centers for Disease Control and Prevention. DHHS (NIOSH) Publication No. 2002129; April 2002.

[5] Steenland K, Sanderson W. Lung cancer among industrial sand workers exposed to crystalline silica. Am J Epidemiol 2001; 153: 695-703, (Study Report).

[6] McDonald JC, McDonald AD, Hughes JM, Rando RJ, Weill H. Mortality from lung and kidney disease in a cohort of North American industrial sand workers: an update. Ann Occup Hyg 2005; 49(5): 367-73.

[7] Calvert GM, Rice FL, Boiano JM, Sheehy JW, Sanderson WT. Occupational silica exposure and risk of various diseases: an analysis using death certificates from 27 states of the United States. Occup Environ Med 2003; 60(2): 122-9.

[8] Steenland K, Sanderson W, Calvert GM. Kidney disease and arthritis in a cohort study of workers exposed to silica. Epidemiology 2001; 12(4): 405-12.

[9] Steenland K. One agent, many diseases: exposure-response data and comparative risks of different outcomes following silica exposure. Am J Ind Med 2005; 48(1): 16-23.

[10] Parks CG, Conrad K, Cooper GS. Occupational exposure to crystalline silica and autoimmune disease. Environ Health Perspect 1999; 107(Suppl 5): 793-802.

[11] Erdogdu G, Hasirci V. An overview of the role of mineral solubility in silicosis and asbestosis. Environ Res 1998; 78: 38-42.
[12] Silicosis Fact Sheet. N238. World Health Organization, May 2000. Accessed March 5, 2010. Available from: www.who.int/ mediacentre/factsheets/fs238/en/

[13] Maciejewska A. Occupational exposure assessment for crystalline silica dust: approach in Poland and worldwide. Int J Occup Med Environ Health 2008; 21(1): 1-23.

[14] Center for Disease Control and Prevention (US). Silicosis mortality, prevention, and control. MMWR Morb Mortal Wkly Rep 2005; 54: 16.

[15] Johnson NF. Phagosomal $\mathrm{pH}$ and glass fiber dissolution in cultured nasal epithelial cells and alveolar macrophages: a preliminary study. Environ Health Perspect 1994; 102(Suppl 5): 97-103.

[16] Nilsen A, Nyberg K, Camner P. Intraphagosomal $\mathrm{pH}$ in alveolar macrophages after phagocytosis in vivo and in vitro of fluoresceinlabeled yeast particles. Exp Lung Res 1988; 14: 197-207.

[17] Nyberg K, Johansson U, Johansson A, Camner P. Phagolysosomal $\mathrm{pH}$ in alveolar macrophages. Environ Health Perspect 1992; 97: 149-52.

[18] Kreyling WG. Intracellular particle dissolution in alveolar macrophages. Environ Health Perspect 1992; 97: 121-6.

[19] Lundborg M, Johard U, Johansson A, et al. Phagolysosomal morphology and dissolution of cobalt oxide particles by human and rabbit alveolar macrophages. Exp Lung Res 1995; 21: 51-66.

[20] Guthrie GD Jr. Mineral properties and their contributions to particle toxicity. Environ Health Perspect 1997; 105: 1003-9.

[21] Christensen SR, Jensen SL, Guldberg M, Kamstrup O. Effect of chemical composition of man-made vitreous fibers on the rate of dissolution in vitro at different pHs. Environ Health Perspect 1994; 102: 83-6.

[22] Mattson SM. Glass fiber dissolution in simulated lung fluid and measures needed to improve consistency and correspondence to in vivo dissolution. Environ Health Perspect 1994; 102: 87-90.

[23] Thelohan S, de Meringo A. In vitro dynamic solubility test: influence of various parameters. Environ Health Perspect 1994; 102: 91-6.

[24] Kanapilly GM, Raabe OG, Goh CHT, Chimenti RA. Measurement of in vitro dissolution of aerosol particles for comparison to in vivo dissolution in the lower respiratory tract after inhalation. Health Phys 1973; 24: 497-507.

[25] Baillif P, Touray JC. Chemical behavior of aluminum and phosphorus during dissolution of glass fibers in physiological saline solutions. Environ Health Perspect 1994; 102: 77-81.

[26] Midlander K, Wallinder IO, Leygraf C. In vitro studies of copper release from powder particles in synthetic biological media. Environ Pollut 2007; 145, 1: 51-9.

[27] De Meringo A, Morscheidt C, Thelohan S, Tiesler H. In vitro assessment of biodurability: acellular systems. Environ Health Perspect Suppl 1994;102: S5. 